\title{
Nutritional Behaviors and Perceived Barriers Among University Students: A Cross-Sectional Study
}

\author{
Abdul-Monim Batiha ${ }^{1}$ \\ ${ }^{1}$ Faculty of Nursing, Philadelphia University, Amman, Jordan \\ Correspondence: Abdul-Monim Batiha, Faculty of Nursing, Philadelphia University, Amman, Jordan. E-mail: \\ abatiha@philadelphia.edu.jo; abatiha@gmail.com
}

Received: September 15, 2018 Accepted: October 22, 2018 Online Published: November 5, 2018

doi:10.5539/gjhs.v10n12p21

URL: https://doi.org/10.5539/gjhs.v10n12p21

\begin{abstract}
Purpose: This study was a) performed to evaluate to what degree Jordanian university students display healthy nutritional behavior, b) which socio-demographic variables impact on it, and c) to identify perceived barriers toward not eating healthy foods.
\end{abstract}

Method: A cross-sectional descriptive survey based on a questionnaire, was completed by Jordanian university students $(n=1.180)$.

Results: Students show a low level of a nutritional behaviors score (10 from 20). The most common types of food/drink consumed were caffeine drinks and the rarely or never consumed one was fish. The perceived barriers for not eating healthy food reported were: i) Healthy foods are expensive, ii) Lack of time, iii) Poor choice of healthy foods, iv) living alone at home, v) Don't know how to cook, and vi) Don't like/enjoy healthy foods.

Conclusions: Increased nutritional awareness and healthier nutrition are needed to improve nutritional behavior because it connected with improving health status and academic achievement. Perceived barriers for not eating healthy food should be considered in planning university nutritional programs.

Keywords: barriers, behaviors, cross-sectional, Jordan, lifestyle, nutrition, students, university

\section{Introduction}

Health and nutrition are inseparably intertwined; put simply: "Healthy nutrition promotes health." While both health and illness can be influenced by nutrition, health experts believe that nutrition has a major effect on health (El Ansari et al., 2011). Many of the major health problems in developing and developed countries are related to individual behavior, such as dietary habits, tobacco and drug use, and inadequate levels of exercise. Changing one's nutrition is an important opportunity for decreasing illness and for enhancing health throughout one's lifespan (El Ansari et al., 2011; Alhalaiqa et al., 2017).

These choices reflect the individual unique cultural, ethnic, religious and socio-economic beliefs (El Ansari et al., 2011; Alhalaiqa et al., 2017). These behaviors are powerfully reinforced each day as the child grows up. As well as the family, outside influences such as peers and media may have health consequences and impacts (Camhi et al., 2015; Alazzam et al., 2017; Tawalbeh et al., 2015).

The most important factor working against many cardiovascular diseases, metabolic disorders, cancers, and other related diseases is following a proper lifestyle through ensuring healthy nutrition and practicing physical activity (Djordjević-Nikić et al., 2013; Batiha et al., 2015). Unhealthy nutritional behavior, physical inactivity, substance abuse, smoking, and alcohol consumption is commonly seen among university students globally (Ji et al., 2015).

Present university students are the future leaders in various communities, countries, and organizations. In their university years, students make their own decisions about their nutrition preferences and health status (Deliens et al., 2015). Life at the university constitutes a new and competitive academic and social environment, which may have both positive and negative effects on the health of students; an environment which certainly brings new challenges to individuals who may, or may not, be able to deal with them (Deliens et al., 2015). Negative nutritional behavior during university years may last or continue for the remaining of the humans' life and could lead to an increased risk of contracting, or being affected by, serious diseases (Ji et al. 2015; Deliens et al., 2015) Additionally, many studies have suggested that unhealthy actions related to diets, smoking, inadequate exercising, 
drug abuse, and consuming alcohol, are popular among university students worldwide (Camhi et al., 2015). Ammouri (2008) stated that the percentage of adults in Jordan who participated in health promotion behavior including nutritional habits was a small percentage ranging from (30.1 to $76.7 \%)$. He indicated that there were demographic factors that affect an individual's involvement in health promotion behavior: gender, age, and income.

Young people's minimal knowledge about healthy and risky behavior poses an obstacle to successful health promotion strategies (Alba et al., 2015). Therefore, health-protecting behavior is directed toward reducing risky activities and promoting healthy ones, in order to reduce the probability of an individual encountering illness or injury (Alba et al., 2015). It is possible to summarize several categories of healthy behavior which can be chosen by a healthy adult to make decisions relating to positive health promotion. These categories including: adequate nutritional intake, medical checkup, avoiding smoking, prevention and control of hypertension, regular dental care, moderate exercise that can be practiced two or three times weekly, reducing alcohol consumption, sleeping at least 7 hours at night, self-examination of breast and testicles that is conducted regularly, observing cancer warning signs and taking necessary action in this regard. Such positive health behaviors, done by male and female, may help to prevent illness or injury, dental caries, becoming overweight, and avoiding many other hazards (Laska et al., 2015; Obead et al., 2014). To help males and females to work on personal health risks, community health nurses conduct several basic preventive activities. Their main concern is to help individuals to learn about health problems that can be prevented and health behavior that can cause illness. Nurses can play a major role in increasing a population's awareness of healthy nutritional behavior and how to improve it. This goal can be achieved by means of carrying out health education programs and counseling vulnerable groups in various settings such as schools, universities, industry and medical centers (Edward et al., 2015). A Jordanian study conducted by Abu- Mogli et al. (2010) evaluated the impact of an education package on the kinds of food, exercise, and nutrition practiced by university students. The study suggested that training had a positive effect on enhancing healthy behavior.

Consequently, nurses can be responsible for assessing, planning and evaluating health promotion programs including nutritional behavior in the community, to support social well-being, decrease health risks, promote personal development and even self-actualization (Musaiger et al., 2017).

Recognition of barriers toward not eating healthy foods is one of the leading variables impacting food options. Croll et al. (2001) identified that barriers toward not eating healthy foods in adolescents involve an absence of time, limited accessibility of healthier food in schools.

\subsection{Aims}

The aims of this study were:

- To evaluate to what degree Jordanian university students display healthy nutritional behavior

- Which socio-demographic factors influence nutritional behavior

- To identify perceived barriers toward not eating healthy foods.

\section{Methods}

\subsection{Design}

A cross-sectional descriptive design by using a self-administered questionnaire was performed among universities students in Jordan.

\subsection{Sample and Settings}

Utilizing randomly sampling in two stages 1) we used a stratified sampling method by dividing Jordanian universities into 5 homogeneous universities before starting the survey. 2) 216 students were chosen from each university. We estimated the dropout rate to get the sample size of 1180 . Students were selected by simple random sampling technique from each university; each student has the same chances of being chosen at any stage during the sampling process.

\subsection{Ethical Principles}

The study obtained agreement from the institutional review board (IRB) of Philadelphia University Ethics Committee. The study was completely described to students and verbal consent was provided prior to the collection of data.

Written approval was obtained from related institutions before data collection. In addition, participants were informed in advance about the research objective. Moreover, the confidentiality principle was maintained. 
Questionnaires were delivered and collected during class time after permission was gained from the lecturer. On average students needed 15-20 minutes to complete the forms; they did not receive any rewards for doing so. A details sheet was delivered with the survey to outline the aims and objectives of the study. Furthermore, all students were told that their contribution was 'unpaid' and 'confidential'.

\subsection{Procedure}

Data were gathered between January and April 2017. Students were asked to get involved in the study in their classes. The study was described to the students by research assistants, and a cover letter was given which offered additional information. Students were given adequate time to complete the questionnaires. Researchers were present in the classrooms to assist students in case they needed any help or had any concerns. The questionnaires were returned anonymously at the end of the allocated time. Response rates were identified by comparing the number of the collected questionnaires with attendance rosters of the classes where questionnaires had been distributed, as well as with the rosters of the students registered in each class.

\subsection{Data Collection Instruments}

Three instruments were used to gather the information for this study:

1) Sociodemographic characteristics including age, sex, marital status, income, and clinical demographics: height, weight, smoking status.

2) "Healthy Lifestyle Scale for University Students (HLSUS)" (Dong et al., 2012) [18]. HLSUS was established based on Pender's Health Promotion Model, it demonstrates good test-retest reliability and high internal consistency $(\alpha=0.87$ ) that can be used by university students (Dong et al., 2012). Nutritional behavior scale is subscale of HLSUS and consists of 4 items; the frequency of documented nutritional behaviors was acquired applying a self-reporting Likert scale with a 5-point answer format, "never, rarely, sometimes, usually, and always," ranging from 1 to 5 . The total score acquired from the scale indicates the degree of nutritional behaviors. The minimum score is 4 and the maximum is 20 . A greater score suggests that the student performs a greater level of the nutritional behaviors (Dong et al., 2012; Aminisani et al., 2016).

3) The frequency of consumption of different food types and perceived barriers to not eating more healthy foods was developed based on literature review (Aminisani et al., 2016; Guernsey and Alderney Healthy Lifestyle Survey, 2013) and fit the purpose of this study.

\subsection{Data Analysis}

The Statistical Package for Social Science (SPSS, version 17) was used to analyze the data. Frequencies and proportions were calculated to compute discrepancies between males and females by making use of chi-square analysis. Percentages distribution, frequencies, mean values, and the standard deviation were used in data analysis. Results have been considered statistically significant if the $P$ value was $<0.05$.

\section{Results}

Table 1 displays the general health characteristics of Jordanian students. 1,180 fully-completed questionnaires were returned out of the 1,300 originally distributed; a response rate of $90.8 \%$. The mean age of students who participated in the study was $23.3 \pm 6.6$. Slightly more than half of the participants were males $(55.6 \%)$.

Male students were considered overweight $(26.9 \%)$ or obese $(9.9 \%)$ in comparison with females, with $15 \%$ overweight and, $4.5 \%$ obese. Students were asked to state if they had any 'chronic health problems'. The majority of students reported brushing twice daily with toothpaste. More than half of the male respondents $(59.2 \%)$ and $52.5 \%$ of the female participants reported that they had medical insurance coverage. 
Table 1. Socio-demographic characteristics of the students $(n=1180)$

\begin{tabular}{|c|c|c|c|}
\hline Variable & & Frequency & $\%$ \\
\hline \multirow{2}{*}{ Gender } & Male & 594 & 50.3 \\
\hline & Female & 586 & 49.7 \\
\hline \multirow{4}{*}{ Marital status } & Single & 920 & 78 \\
\hline & Married & 198 & 16.8 \\
\hline & Widowed & 46 & 3.9 \\
\hline & Divorced & 16 & 1.4 \\
\hline \multirow{3}{*}{ With home do you live? } & Alone & 180 & 15.3 \\
\hline & Family(mother, father, kids, wife, siblings) & 843 & 71.4 \\
\hline & Others & 157 & 13.3 \\
\hline \multirow{2}{*}{ Health insurance } & Insured & 666 & 56.4 \\
\hline & Not-insured & 514 & 43.6 \\
\hline \multirow{2}{*}{ Do you work? } & Yes & 392 & 33.2 \\
\hline & No & 788 & 66.8 \\
\hline \multirow{4}{*}{ Family monthly Income (JD) } & Below 300 & 149 & 12.6 \\
\hline & $300-600$ & 147 & 12.5 \\
\hline & $601-1000$ & 589 & 49.9 \\
\hline & Above 1000 & 294 & 24.9 \\
\hline \multirow{3}{*}{ Do you smoke? } & Yes & 408 & 34.6 \\
\hline & No & 741 & 62.8 \\
\hline & I was smoker & 31 & 2.6 \\
\hline \multirow{2}{*}{ Relative health history } & Yes & 795 & 67.4 \\
\hline & No & 385 & 32.6 \\
\hline \multirow{5}{*}{ Type of disease } & Diabetes & 178 & 22.4 \\
\hline & Hypertension & 200 & 25.1 \\
\hline & Heart diseases & 28 & 3.5 \\
\hline & Cancer & 17 & 2.1 \\
\hline & Other/Co-morbid & 381 & 47.9 \\
\hline \multirow{2}{*}{ Self-health history of chronic disease } & Yes & 156 & 13.2 \\
\hline & No & 1024 & 86.8 \\
\hline
\end{tabular}

Table 2 shows the mean scores of the nutrition behavior for university students. Students show a low level of the nutritional behaviors score with an average of students was $(10 \pm 3.32)$ (lower score $=4$ and upper score $=20$ ). Majority of the students give consideration to restoring fluids during exercise $(n=1057,89.6 \%)$, and most of them never or rarely purposely select a diet low salt, fat, and cholesterol $(n=997,84.5 \%)$.

To evaluate the association of demographic characteristics on nutritional behaviors, various statistical tests were performed. The significant variables were:

- Marital status $\left(\chi^{2}\right.$ test, $\left.p=0.000\right)$

- Self-health history of chronic disease $\left(\chi^{2}\right.$ test, $\left.p=0.000\right)$

- Smoking status $\left(\chi^{2}\right.$ test, $\left.p=0.000\right)$

- Higher family monthly income $\left(\chi^{2}\right.$ test, $\left.p=0.10\right)$

- Students who still live at home $\left(\chi^{2}\right.$ test, $\left.p=0.000\right)$

- Working ( $\chi^{2}$ test, $p=0.000$ ).

The only variable that had no effect on the nutritional behaviors was gender ( $\chi^{2}$ test, $p=0.21$ ). 
Table 2. Nutrition behavior for university students $(n=1180)$

\begin{tabular}{|c|c|c|c|c|c|c|}
\hline \multirow{3}{*}{ Dimension } & Never & Rarely & Sometimes & Usually & Always & \multirow{3}{*}{$X(S D)$} \\
\hline & 1 & 2 & 3 & 4 & 5 & \\
\hline & $n(\%)$ & $n(\%)$ & $n(\%)$ & $n(\%)$ & $n(\%)$ & \\
\hline $\begin{array}{l}\text { Pay attention to replenishing fluids during } \\
\text { exercise }\end{array}$ & $32(2.7)$ & $55(4.7)$ & $35(3)$ & $610(51.7)$ & $447(37.9)$ & \multirow{4}{*}{$10(3.32)$} \\
\hline $\begin{array}{l}\text { Drink at least } 800 \mathrm{~mL} \text { ( } \sim 5 \text { disposable paper cups }) \\
\text { of water daily }\end{array}$ & $46(3.9)$ & $111(9.4)$ & $26(2.2)$ & $571(48.4)$ & $426(36.1)$ & \\
\hline $\begin{array}{l}\text { Eat foods rich in dietary fiber (e.g. fruit, } \\
\text { vegetables) }\end{array}$ & $22(1.9)$ & $523(44.3)$ & $504(42.7)$ & $111(9.4)$ & $20(1.7)$ & \\
\hline $\begin{array}{l}\text { Consciously choose a diet low in fat, saturated } \\
\text { fat, salt, and cholesterol }\end{array}$ & $525(44.5)$ & $472(40)$ & $91(7.7)$ & $63(5.3)$ & $30(2.5)$ & \\
\hline
\end{tabular}

Table 3 reveals the frequency of consuming different types of food. Students were asked about the portions of vegetables and fruit they consumed weekly. The most common types of foods/drinks which are consumed more than 7 times a week were: caffeine drinks (37.2\%), vegetables $(15.2 \%)$, milk and milk products $(14.5 \%)$, salad $(11.7 \%)$, fruit $(9.9 \%)$, but, the rarely or never consumed foods per week were: fish $(1.6 \%)$ and beans $(1.7 \%)$.

Table 3. The frequency of consumption of different food types ( $n=1180)$

\begin{tabular}{|c|c|c|c|c|c|c|}
\hline & $\begin{array}{l}\text { Rarely/ } \\
\text { Never } \\
n(\%)\end{array}$ & $\begin{array}{l}\text { once a } \\
\text { week } \\
n(\%)\end{array}$ & $\begin{array}{l}\text { Once a } \\
\text { Week } \\
n(\%)\end{array}$ & $\begin{array}{l}2-3 \\
\text { times a } \\
\text { week } \\
n(\%)\end{array}$ & $\begin{array}{l}4-6 \\
\text { times a } \\
\text { week } \\
n(\%)\end{array}$ & $\begin{array}{l}7+\text { times } \\
\text { a week } \\
n(\%)\end{array}$ \\
\hline Fruit (tinned or fresh) & $140(11.9)$ & $207(17.5)$ & $229(19.4)$ & $259(30.4)$ & $128(10.8)$ & 117(9.9) \\
\hline Fruit juice & $102(8.7)$ & $176(23.4)$ & $252(21.4)$ & $297(25.2)$ & $157(13.3)$ & $96(8.1)$ \\
\hline Salad & $168(14.3)$ & $159(13.5)$ & $170(14.4)$ & $398(33.7)$ & $147(12.5)$ & $138(11.7)$ \\
\hline $\begin{array}{l}\text { Vegetables (tinned, frozen or } \\
\text { fresh- not potatoes) }\end{array}$ & $135(11.4)$ & $138(11.7)$ & $164(13.9$ & $398(33.7)$ & $166(14.1)$ & $179(15.2)$ \\
\hline Meat or chicken & $153(13)$ & $157(13.3)$ & $180(15.3)$ & $396(33.6)$ & $181(15.3)$ & $113(9.6)$ \\
\hline Milk \& Milk Products & $225(19.9)$ & $200(16.9)$ & $183(15.5)$ & $245(20.8)$ & $146(12.4)$ & $171(14.5)$ \\
\hline fish & $270(22.8)$ & $487(41.3)$ & $250(21.2)$ & $102(8.6)$ & $52(4.4)$ & $19(1.6)$ \\
\hline Nuts & 131(11.1) & $375(31.8)$ & $238(20.2)$ & $258(21.9)$ & $108(9.2)$ & $70(5.9)$ \\
\hline $\begin{array}{l}\text { Beans or pulses e.g. baked beans, } \\
\text { chickpeas, lentils }\end{array}$ & $181(15.3)$ & $307(26)$ & $320(27.1)$ & $258(21.9)$ & $94(8)$ & $20(1.7)$ \\
\hline High calorie Fast food & $149(12.7)$ & $326(27.6)$ & $221(18.7)$ & $270(22.9)$ & $114(9.7)$ & $100(8.5)$ \\
\hline High-calorie fizzy drinks & $746(63.3)$ & $185(15.7)$ & $71(6)$ & $76(6.4)$ & $37(3.1)$ & $65(5.5)$ \\
\hline Cola & $271(23)$ & $286(24.2)$ & $143(12.1)$ & $188(15.9)$ & $124(10.5)$ & $168(14.2)$ \\
\hline $\begin{array}{l}\text { Caffeine drinks (coffee, Nescafe, } \\
\text { cola) }\end{array}$ & $174(14.8)$ & $120(10.2)$ & $77(6.5)$ & $174(14.7)$ & $196(16.6)$ & $439(37.2)$ \\
\hline $\begin{array}{l}\text { Herbal drinks } \\
\text { chamomile....etc.) }\end{array}$ & $294(24.9)$ & $329(27.9)$ & $171(14.5)$ & $179(15.2)$ & $99(8.4)$ & $108(9.2)$ \\
\hline
\end{tabular}

Table 4 depicts over two-thirds of students (74\%) reported that they were currently eating the healthiest food possible. The most common perceived barriers behind not eating healthy food were that i) Healthy foods are expensive(42.9\%), ii) Lack of time(18.6\%), iii) Poor choice of healthy foods (13.5), iv) living alone at home 
(10.4\%), v) don’t know how to cook healthily (6.3\%), and vi) Don’t like/enjoy healthy foods (1.4\%).

Table 4. Barriers to not eating healthy food

\begin{tabular}{llll}
\hline \multirow{2}{*}{ Eating food } & & F & \% \\
\hline & I am currently eating as healthy as possible & 876 & 74.2 \\
\cline { 2 - 4 } & I care to eat food that maintains my weight regardless of quality & 835 & 70.7 \\
\cline { 2 - 4 } Barriers to not eating healthy food & I'm living alone at home & 123 & 10.4 \\
\cline { 2 - 4 } & Healthy foods are expensive & 506 & 42.9 \\
\cline { 2 - 4 } & I don't know how to cook healthily & 74 & 6.3 \\
\cline { 2 - 4 } & I do not have time & 220 & 18.6 \\
\cline { 2 - 4 } & Don't like/enjoy healthy foods & 17 & 1.4 \\
\cline { 2 - 4 } & Poor choice of healthy foods in places where I shop & 159 & 13.5 \\
\cline { 2 - 4 } & others & 81 & 6.9 \\
\hline
\end{tabular}

\section{Discussion}

The main finding of this study shows a low level of the nutritional behaviors score (NBS) for university students with an average of 10 out of 20. This result is lower than the Chinese study (NBS=13.87) (Dong et al., 2012). And Turkish study (NBS = 15.17) (Hacihasanoğlu et al., 2011). The result of low nutritional behavior score can be explained by perceived barriers faced by university students (table 4): i) Healthy foods are expensive, ii) Lack of time, III) Poor choice of healthy foods, IV) living alone at home, V) don't know how to cook healthily, and vi) Don't like/enjoy healthy foods.

Regarding nutrition, the sample of this study revealed that caffeine (37.2\%), vegetables (15.2\%), milk and milk products (14.5\%), salad (11.7\%) and fruit (9.9\%) are the most common types of food/drink which are consumed daily. These results are in line with El Ansari et al. (2011) who suggested that $16.5 \%$ of the females and $11.3 \%$ of the males consumed 5 vegetable/fruit meals or more every day. The result compares positively with university students in Germany, where approximately $95 \%$ of the first year students ate less than five meals of fruit and vegetables daily (Keller et al., 2008). In Iran, diet patterns showed that the portions of vegetable and whole grains in participants' diets were below the recommended amounts (Mazloomi et al., 2013).

In comparison, in Hong Kong, 36\% of the female, and 34\% of the male university students had 2 or 4 portions of fruit every day; $55 \%$ of the females and $41 \%$ of the males had 3 to 5 portions of vegetables every day (Lee $\&$ Loke, 2005).

In the USA, $8.5 \%$ of the university students revealed that they ate 5 or more meals of vegetables and fruit every day. To decrease the possibility of exposure to a chronic disease, 18 to 24-year-old students can follow a simple and inexpensive prevention strategy by increasing fruit and vegetable consumption (Dietz et al., 2016). Although eating dairy products and fruits is healthy, our students also consumed high levels of caffeine. This consumption might result from the students considering caffeine to be a brain stimulant which increases students' concentration levels. $400 \mathrm{mg}$ daily, or 5 cups of coffee, are not considered as harmful, according to Nehlig (2015). Moreover, caffeinated drinks have several beneficial effects on the brain. They may enhance performance and health, improve focus, enhance feelings and restrict depressive disorders (Nehlig, 2015). However, caffeine drinks may have a negative effect on sleep, especially among delicate people. It may also serve to at least partially increase stress levels in particularly delicate individuals (Nehlig, 2015).

This study showed that university students do not eat fish and beans which are the main sources of protein, omega-3 fatty acid, and iodine (Laska et al., 2015). This deficit makes such students liable to develop, or suffer from, thyroid dysfunction (Papanikolaou et al., 2014). Therefore, universities should introduce courses that highlight the importance of a balanced diet on health and the benefits of consuming seafood. These results are in agreement with a US study which showed that many members of the US participants are not eating suggestions for omega-3 fatty acid intake (Papanikolaou et al., 2014).

The present study showed that the percentage of male students who are current smokers was $51.2 \%$, compared to $14.8 \%$ of the female students. This difference may be attributed to the fact that females start smoking later than 
men in developing countries and generally have lower rates of smoking daily (American College Health Association, 2009). This smoking behavior is mostly the result of social, cultural, religious or economic factors. This finding is incongruent with UK students, where the percentage of students who had never smoked was: $73 \%$ females and $71 \%$ males. Also, in the United States of America, $66.0 \%$ of students reported that they had never used cigarettes (American College Health Association, 2009). The levels of Jordanian student non-smoking students are considered lower than the levels described among Spanish (67.6\%), German (75.5\%) and Lithuanian (76\%) students who indicated that they had never smoked or they did so on only a few special or particular occasions (Stock et al., 2003). The high levels of current smoking in this study may be because the students consider smoking as a symbol of independence, maturity, virility, sophistication and/or a rebellion against family ideas. It is important to stress that the high prevalence of smoking among male students in Jordan makes them vulnerable to many diseases; in particular lung cancer and heart-related.

The unhealthy behavior of university students such as high consumption of convenience food (junk food) and improper self-care may expose them to chronic diseases at later stages in their lives.

In conclusion, the university students in this study appeared to be practicing only moderately healthy nutrition behavior. This outcome calls for increased awareness, support and encouragement to adopt healthier nutrition among students, through comprehensive, national preventive strategies. Serious regulations and policies should be applied by universities in order to improve healthy lifestyles among their students.

The significant restriction of the present study that cross-sectional design may pose an obstacle that hinders the possibility of inferring a cause-effect relationship. Self-administering questionnaires had reporting bias which limited the generalizability of the study.

\section{Recommendations}

Informed by the results of this study, it is recommended that:

1) Increased nutritional awareness is needed through mass media and formal and informal channels about health knowledge. Appropriate campaigns should be launched targeting university students and the general public.

2) Universities should support and encourage healthier nutrition among students, such as having healthy meals.

3) Perceived barriers to not eating healthy food should be considered in planning university nutritional programs.

4) School and university programs should be implemented to assist young adults to develop healthy nutritional behavior, which should be included in the curriculum.

5) Comprehensive, national preventive strategies should be adopted to enhance adolescents' and young adults' knowledge of healthy, as well as unhealthy, behavior.

6) Yearly periodic medical examination for university students should be encouraged, with the aim of early nutritional deficiency detection.

7) Further research is required to explore factors which affect nutritional behaviors among various communities and to come up with more details about family nutrition and its effect on their siblings' health and the health of future generations.

\section{Funding}

The study was funded by Philadelphia University/Jordan.

\section{Acknowledgments}

The author wishes to extend their thanks and gratitude to all the universities and students who contributed to bringing this research to life. Authors received funds with thanks from Philadelphia University to collect data and covering the publishing process.

\section{Competing Interests Statement}

The author declares that they have no competing interests.

\section{References}

Abu-Moghli, F. A., Khalaf, I. A., \& Barghoti, F. F. (2010). The Influence of a Health Education Programme on Healthy Lifestyles and Practices among University Students. International Journal of Nursing Practice, 16, 
35-42. https://doi.org/10.1111/j.1440-172X.2009.01801.x

Alazzam, M., Albashtawy, M., Aljezawi, M., Batiha, A. M., Freij, M., Khasawneh, B., \& Alhalaiqa, F. (2017). Pattern of interaction and relationships between family members. International Journal of Health, 5(1), 45-47 https://doi.org/ 10.14419/ijh.v5i1.7291

Alba, L. H., Badoui, N., \& Gil, F. (2015). Attitude toward preventive counseling and healthy practices among medical students at a Colombian university. Frontiers of Medicine, 9(2), 251-259. https://doi.org/10.1007/s11684-015-0393-z

Alhalaiqa, F., Al-Nawafleh, A., Batiha, A. M., Masa'deh, R., \& Al-Razek, A. A. (2017). A descriptive study of adherence to lifestyle modification factors among hypertensive patients. Turkish journal of medical sciences, 47(1), 273-281. https://doi.org/10.3906/sag-1508-18

American College Health Association-National College Health Assessment Spring 2008 Reference Group Data Report (Abridged). (2009). Journal of American College Health, 57(5), 477-488. https://doi.org/10.3200/JACH.57.5.477-488

Aminisani, N., Shamshirgaran, S. M., Jafarabadi, M. A., Sadeghi-Bazargani, H., Amini, A., Abedi, L., \& Kanani, S. (2016). Reliability and validity of the Persian version of the healthy lifestyle scale for university students. Res Dev, 5(2), 79-84. https://doi.org/10.15171/rdme.2016.016

Ammouri, A. (2008). Demographic Differences in Health Promoting Lifestyle of Adult Jordanians. Jordanian Medical Journal, 42, 1-9.

Batiha, A. M., Obead, K. A., Alhalaiqa, F. N., Kawafha, M. M., El-Razek, A. A., Albashtawy, M., ... Al Ewaidat, H. (2015). Quality of Life and Fatigue among Jordanian Cancer Patients. Iranian Journal of Public Health, 44(12), 1704.

Camhi, S. M., Crouter, S. E., Hayman, L. L., Must, A., \& Lichtenstein, A. H. (2015). Lifestyle Behaviors in Metabolically Healthy and Unhealthy Overweight and Obese Women: A Preliminary Study. Plos ONE, 10(9), 1-12. https://doi.org/10.1371/journal.pone.0138548

Croll, J. K., Neumark-Sztainer, D., \& Story, M. (2001). Healthy eating: what does it mean to adolescents?. Journal of nutrition education, 33(4), 193-198. https://doi.org/10.1016/S1499-4046(06)60031-6

Deliens, T., Deforche, B., De Bourdeaudhuij, I., \& Clarys, P. (2015). Determinants of physical activity and sedentary behaviour in university students: a qualitative study using focus group discussions. BMC Public Health, 15201. https://doi.org/10.1186/s12889-015-1553-4

Dietz, W. H., Douglas, C. E., \& Brownson, R. C. (2016). Chronic disease prevention: tobacco avoidance, physical activity, and nutrition for a healthy start. Jama, 316(16), 1645-1646. https://doi.org/10.1001/jama.2016.14370

Djordjević-Nikić, M., Dopsaj, M., \& Vesković, A. (2013). Nutritional and physical activity behaviours and habits in adolescent population of Belgrade. VojnosanitetskiPregled: Military Medical \& Pharmaceutical Journal of Serbia, 70(6), 548-554. https://doi.org/10.2298/VSP1306548D

Dong, W., Xiao-hui, X., \& Xian-bo, W. (2012). The healthy lifestyle scale for university students: development and psychometric testing. Australian journal of primary health, 18(4), 339-345.

Edward, K., Warelow, P., Hemingway, S., Hercelinskyj, G., Welch, A., McAndrew, S., \& Stephenson, J. (2015). Motivations of nursing students regarding their educational preparation for mental health nursing in Australia and the United Kingdom: a survey evaluation. BMC Nursing, 14(1), 1-5. https://doi.org/10.1186/s12912-015-0084-8

El Ansari, W., Stock, C., John, J., Deeny, P., Phillips, C., Snelgrove, S., ... Mabhala, A. (2011). Health promoting behaviours and lifestyle characteristics of students at seven universities in the UK. Central European journal of public health, 19(4), 197. https://doi.org/10.21101/cejph.a3684

El Ansari, W., Stock, C., John, J., Deeny, P., Phillips, C., Snelgrove, S., ... Mabhala, A. (2011). Health promoting behaviours and lifestyle characteristics of students at seven universities in the UK. Central European journal of public health, 19(4), 197. https://doi.org/10.21101/cejph.a3684

Guernsey and Alderney Healthy Lifestyle Survey 2013. Retrieved from https://www.gov.gg/CHttpHandler.ashx?id=102497\&p=0

Hacıhasanoğlu, R., Yıldırım, A., Karakurt, P., \& Sağlam, R. (2011). Healthy lifestyle behaviour in university 
students and influential factors in eastern Turkey. International Journal of Nursing Practice, 17(1), 43-51. https://doi.org/10.1111/j.1440-172X.2010.01905.x

Ji, Y., Sun, L., Zhang, Y., \& Wang, Y. (2015). Social determinants of chronic diseases related behaviors in primary school students in Beijing City. Journal of Hygiene Research, 44(5), 703-710.

Keller, S., Maddock, J. E., Hannöver, W., Thyrian, J. R., \& Basler, H. D. (2008). Multiple health risk behaviors in German first year university students. Preventive medicine, 46(3), 189-195. https://doi.org/10.1016/j.ypmed.2007.09.008

Laska, M. N., Hearst, M. O., Lust, K., Lytle, L. A., \& Story, M. (2015). How we eat what we eat: identifying meal routines and practices most strongly associated with healthy and unhealthy dietary factors among young adults. Public Health Nutrition, 18(12), 2135-2145. https://doi.org/10.1017/S1368980014002717

Lee, R. L., \& Loke, A. J. (2005). Health-promoting behaviors and psychosocial well-being of university students in Hong Kong. Public health nursing, 22(3), 209-220. https://doi.org/10.1111/j.0737-1209.2005.220304.x

Mazloomi, M. S., Fazelpour, S., \& Askarshahi, M. (2013). Health-Promoting Behaviors and Psychosocial Well-Being of University ShahidSadoqi Yazd Academic Staff in Iran. Journal of Ilam university of medical sciences, 21(3), 12-21.

Musaiger, A. O., Awadhalla, M. S., Al-Mannai, M., AlSawad, M., \& Asokan, G. V. (2017). Dietary habits and sedentary behaviors among health science university students in Bahrain. International Journal of Adolescent Medicine And Health, 29(2). https://doi.org/10.1515/ijamh-2015-0038

Nehlig, A. (2015). Effects of coffee/caffeine on brain health and disease: What should I tell my patients? Practical neurology, practneurol-2015.

Obead, K. A., Batiha, A. M., Al-Jauissy, M. S., Alhalaiqa, F., \& AlBashtawy, M. (2014). Impact of radiotherapy treatment on Jordanian cancer patients' quality of life and fatigue. International Journal of Advanced Nursing Studies, 3(1), 6-12. https://doi.org/10.14419/ijans.v3i1.798

Papanikolaou, Y., Brooks, J., Reider, C., \& Fulgoni, V. L. (2014). US adults are not meeting recommended levels for fish and omega-3 fatty acid intake: results of an analysis using observational data from NHANES 20032008. Nutrition Journal, 13(1), 31. https://doi.org/10.1186/1475-2891-13-31

Stock, C., Kücük, N., Miseviciene, I., Guillén-Grima, F., Petkeviciene, J., Aguinaga-Ontoso, I., \& Krämer, A. (2003). Differences in health complaints among university students from three European countries. Preventive Medicine, 37(6 Pt 1), 535-543. https://doi.org/10.1016/j.ypmed.2003.07.001

Tawalbeh, L. I., Tubaishat, A., Batiha, A.M., Al-Azzam, M., \& AlBashtawy, M. (2015). The relationship between social support and adherence to healthy lifestyle among patients with coronary artery disease in the north of Jordan. Clinical Nursing Research, 24(2), 121-138. https://doi.org/10.1177/1054773813501194

\section{Copyrights}

Copyright for this article is retained by the author(s), with first publication rights granted to the journal.

This is an open-access article distributed under the terms and conditions of the Creative Commons Attribution license (http://creativecommons.org/licenses/by/4.0/). 